\title{
Effects of Short-Term Consumption of a Large Amount of Tea Catechins on Chromosomal Damage, Oxidative Stress Markers, Serum Lipid, Folic Acid, and Total Homocysteine Levels : A Randomized, Double-Blind, Controlled Study
}

\author{
Toshihiro YOSHIKAWA *1, Hiroshi YAMADA ${ }^{* 1}$, Katsuhiko MATSUDA*2, \\ Hitoshi NIINO*3, Yuko M. SAGESAKA*3, Takami KAKUDA*3, \\ Kiichiro TOYOIZUMI*1, Keiji MATSUMOTO*1, Kazuhiro KOSUGE*1, \\ Shinya UCHIDA*1, Satomi ONOUE*1, Shizuo YAMADA*1 \\ and Keizo UMEGAKI*4 \\ *1 Graduate School of Pharmaceutical Sciences, University of Shizuoka, Shizuoka, Japan \\ *2 Shizuoka General Hospital, Shizuoka, Japan \\ *3 Central Research Institute, ITO EN, Ltd., Shizuoka, Japan \\ *4 National Institute of Health and Nutrition, Tokyo, Japan
}

\begin{abstract}
Objective : To evaluate the effects of short-term consumption of a large amount of tea catechins on chromosomal damage, oxidative stress markers, serum lipid, folic acid, and total homocysteine levels in middle-aged healthy volunteers.

Methods : Forty volunteers (40-63 years) participated in a randomized, double-blind study. After a 1-week washout, the catechin group consumed approximately $1069 \mathrm{mg} /$ day of total catechins for 1 week. The micronucleated binucleate cells $(\mathrm{MNi})$ frequency in the cytokinesis-block micronucleus cytome assay, urinary 8hydroxydeoxyguanosine $(8-\mathrm{OHdG})$, isoprostane, lymphocyte and plasma vitamin $\mathrm{C}$, serum lipid, folic acid, and total homocysteine levels were measured at the beginning and end of the intervention.

Results : No significant differences were observed between the catechin and placebo groups in terms of $\mathrm{MNi}$ frequency, urinary 8-OHdG, isoprostane, or lymphocyte and plasma vitamin C levels. The serum LDL-cholesterol level in the catechin group significantly decreased compared with pre-intervention period, and there was a decreased tendency in the catechin group compared with the placebo group, but the difference was not significant $(P=0.105)$. The serum folic acid level decreased $(P=0.073)$ and the total homocysteine level significantly increased in the catechin group $(P=0.029)$. No serious adverse events were observed during the study.

Conclusions : A large amount of tea catechins, which corresponds to approximately 10 cups of green tea per day for 1 week, seemed to be well tolerated, and did not influence chromosomal damage and the oxidative stress markers. Further long-term and large-scale studies are required to clarify the long-term effect of the consumption of a large amount of tea catechins on these markers as well as on improving dyslipidemia.
\end{abstract}

Trial Registration : ClinicalTrials. gov ID, NCT00448513

Key words : catechins, chromosomal damage, oxidative stress, LDL-cholesterol, dyslipidemia

\section{Introduction}

Tea has been consumed since ancient times and is one of the most popular beverages around the world, second to water. About $80 \%$ of the tea production worldwide is black tea, which is the main tea beverage consumed in Europe and North America. Green tea, which is mainly consumed in Asian countries such as China, Korea, and Japan. In the processing of green tea fresh leaves, the leaves are steamed or pan-dried at a high temperature right after plucking, resulting in minimal oxidation of the naturally occurring

Address for Correspondence : YAMADA H. Department of Drug Evaluation \& Informatics, Graduate School of Pharmaceutical Sciences, University of Shizuoka, 52-1 Yada, Suruga-ku, Shizuoka 422-8526, Japan

(Manuscript received February 1, 2011 ; revised December 10, 2011 ; accepted December 16, 2011) 
catechins in the tea leaves. In general, the amount of catechins in green tea is relatively high, up to $30 \%$ of their dry weight. The major catechins are (+)-catechin (C), (-)-epicatechin (EC), $(+)$-gallocatechin $(\mathrm{GC}),(-)$-epigallocatechin (EGC), $(-)$-catechin gallate $(\mathrm{Cg}),(-)$-epicatechin gallate $(\mathrm{ECg}),(-)$-gallocatechin gallate $(\mathrm{GCg})$, and $(-)$-epigallocatechin gallate $(\mathrm{EGCg})^{1)}$. In green tea, particularly, a high amount of EGCg constitutes approximately 50 to $60 \%$ of the total tea catechins.

A considerable amount of scientific research on tea has been conducted over the past several decades ${ }^{2,3)}$, and it has revealed that tea catechins exert various physiological effects that are beneficial to human health, such as antioxidative effect ${ }^{4-7)}$, anticarcinogenic effect ${ }^{8)}$, reduction of dyslipidemia ${ }^{9-13)}$, antiobesitic effect $^{14)}$, reduction of high blood pressure ${ }^{15)}$, antibacterial effect $\mathrm{t}^{16)}$, antiviral effect ${ }^{17)}$, and antiallergic effect ${ }^{18)}$. With regard to the antioxidative effect, Sugisawa et al. ${ }^{6)}$ reported in an in vitro study that physiological concentrations of EGCg less than $1 \mu \mathrm{mol} / \mathrm{L}$ are not genotoxic, but can prevent reactive oxygen speciesinduced chromosomal damage. Hakim et al. ${ }^{7)}$ reported in a clinical study that after 4 months of drinking 4 cups of decaffeinated green tea per day, urinary 8hydroxydeoxyguanosine (8-OHdG), which is one of the oxidative stress markers, significantly decreased. With regard to reduction of dyslipidemia, Koo and $\mathrm{Noh}^{12)}$ reported that green tea or catechins inhibited the intestinal absorption of dietary lipids. Davies et al. ${ }^{13)}$ reported that 5 cups of tea per day for 3 weeks reduced the total and LDL cholesterol levels. According to well-controlled designs, however, there is little clinical evidence of chromosomal damage, antioxidative effect or reduction of dyslipidemia after a large amount consumption of purified tea catechin extracts.

Among the green tea components, catechins may be important with respect to obtaining an antioxidant effect or reducing dyslipidemia. Therefore, more rapid and greater effects would be obtained if large amounts of catechins or purified catechins are administered. On the background, a randomized, double-blind, controlled study was performed to evaluate the influence of short-term consumption of a large amount of tea catechins on chromosomal damage, oxidative stress markers, and serum lipid levels in middle-aged healthy volunteers.

\section{Materials and Methods}

\section{Subjects}

Volunteers of either sex, who were between 40 and 65 years of age, were recruited from the local area of Shizuoka city where the research was performed. The intervention started in November 2007 and ended in August 2008. Volunteers were excluded if they were taking any medications or drugs, if they had allergies to tea or catechins, if they were pregnant women, or if they were taking any dietary supplements containing antioxidants (e.g., vitamin E) or folic acid in the previous 3 months. They were also prohibited from taking these supplements during the entire course of the study.

The study was approved by the ethics committee of the University of Shizuoka and Shizuoka General Hospital, in accordance with the Declaration of Helsinki. Written informed consent was obtained from the subjects before entering the study.

\section{Design and Intervention}

The study was a randomized, double-blind, placebocontrolled, parallel-group design with 1 week of intervention preceded by a 1-week washout period. After the 1-week washout period, the subjects were randomly divided into 2 groups, namely, the catechin group and the placebo group, by using computergenerated random numbers. Randomization was carried out with a stratified block method, and sex and smoking status were selected as stratified factors. During the intervention period, the subjects took 3 capsules containing either catechins or placebo 3 times a day for 1 week. The subjects were instructed to avoid taking the test capsules with meals, and they took the capsules at certain intervals of 30 minutes or more. During the 2 weeks including washout and intervention periods, the subjects were not allowed to drink any tea beverages containing catechins or take any supplements that might affect either their oxidative stress markers or serum lipids. The subjects were also instructed not to make any changes to their usual food intake, alcohol consumption, or physical activity.

Usual tea drinking, alcohol consumption, smoking habit, and physical activity were assessed by a questionnaire at the baseline of random allocation. The subjects were asked to record in their diaries any test capsules taken, any adverse events, or any 
concomitant medications or supplements taken.

\section{Test Substances}

THEA-FLAN 90S (ITO EN, LTD., Tokyo, Japan), containing about $70 \%$ gallated catechin, was used as the test capsule for intervention. The catechin content was measured with high-performance liquid chromatography (HPLC) ${ }^{19)}$. The total catechin content per 3 capsules was $356.48 \mathrm{mg}$, including $270 \mathrm{mg} \mathrm{EGCg}$, $6.78 \mathrm{mg} \mathrm{GCg}, 71.39 \mathrm{mg} \mathrm{ECg}$, and $4.09 \mathrm{mg}$ EGC. In the present study, the subjects allocated to the catechin group took a total amount of $1069.44 \mathrm{mg}$ catechins per day. The placebo capsules were made from inert ingredients and were identical to the active capsules in color, appearance, weight, and odor.

\section{Outcome Measures}

All measurements were performed before and after the intervention period. Blood and urine samples were taken in the early morning after the subjects had fasted overnight. Chromosomal damage in the peripheral blood lymphocytes was assayed using the cytokinesis-block micronucleus (CBMN) method $^{20,21)}$ for cultured lymphocytes. Briefly, heparinized blood from each subject was divided into two parts in culture bottles. Whole blood $(0.5 \mathrm{~mL}$ each) was added to $4.5 \mathrm{~mL}$ of RPMI-1640 culture medium supplemented with $10 \%$ fetal calf serum and $1 \%$ antibiotics. The culture was immediately initiated by adding $0.1 \mathrm{~mL}$ of phytohemagglutinin. Cytochalasin B (final concentration $5.4 \mu \mathrm{g} / \mathrm{mL}$ ) was added at 44 hours to induce binucleated cells. The cells were harvested at 72 hours and treated with hypotonic media for more than 2 min. Slides were prepared using a cytocentrifuge (Shandon Southern Products ; Cheshire, UK). The slides were air-dried for $60 \mathrm{~min}$, fixed with absolute methanol, and then stained with $4 \%$ (v/v) Giemsa's solution in water for $30 \mathrm{~min}$. Chromosomal damage rates were expressed as the number of micronucleated binucleate cells $(\mathrm{MNi})$ per 1000 binucleated cells.

The measurements of urinary $8-\mathrm{OHdG}$ and urinary isoprostane levels were analyzed by enzyme immunoassay methods. For the measurements of vitamin $\mathrm{C}$, lymphocytes and plasma were prepared by centrifugation and the Ficoll gradients method, then immediately treated with metaphosphoric acid (final 5\% wt) wt) to stabilize vitamin $\mathrm{C}^{22}$. These processes were performed within $2 \mathrm{~h}$ under cooled conditions on ice to obtain reliable data. The vitamin $\mathrm{C}$ samples were stored at $-80^{\circ} \mathrm{C}$ until analysis, and the vitamin $\mathrm{C}$ (ascorbic acid, reduced form) levels were measured by HPLC with the electrochemical detector method ${ }^{23)}$. All samples were handled and stored similarly in both groups.

EGCg and epigallocatechin-3-O-(3-O-methyl)gallate (EGCg3" Me) in blood samples was prepared with ethyl acetate and analyzed by HPLC equipped with a coulochem II electrochemical detector (ESA, Inc., Bedford, MA) ${ }^{24)}$.

Other blood and urine samples were analyzed by SRL, Inc. independently. The parameters analyzed included total cholesterol, LDL-cholesterol (LDL-cho), HDL-cholesterol (HDL-cho), triacylglycerol (TG), folic acid, total homocysteine, AST, ALT, $\gamma$-GTP, lactate dehydrogenase, total bilirubin, creatinine, total protein, albumin, sodium, potassium, chloride, red blood cell count, white blood cell count, hemoglobin, hematocrit, and platelet count.

\section{Safety Monitoring}

Adverse events were collected from all subjects who took at least 1 test capsule and were included in the safety analysis. Clinical laboratory blood and urine tests were performed and blood pressure and pulse rates were measured during the pre- and postintervention period for safety monitoring.

\section{Statistical Analyses}

The observed values for each measurement and change (value observed in the post-intervention minus that in the pre-intervention ; $\Delta$ values) were represented by mean (SD). The baseline characteristics of the 2 groups were compared by Fisher's exact test for categorical variables and an unpaired $t$ test. The significance of any inter-group difference in the changes was tested by an unpaired $t$ test. The correlation between the changes in the MNi frequency and the levels of catechins was tested by Pearson's correlation coefficient test. Intra-group comparisons of the data obtained post-intervention period versus preintervention were tested by the paired $t$ test Intergroup comparisons were tested by analysis of covariance to determine if the differences between the groups were significantly different. In each analysis, a $P$ value $<0.05$ was considered to be statistically significant. A safety evaluation, such as adverse events and abnormal findings from clinical 


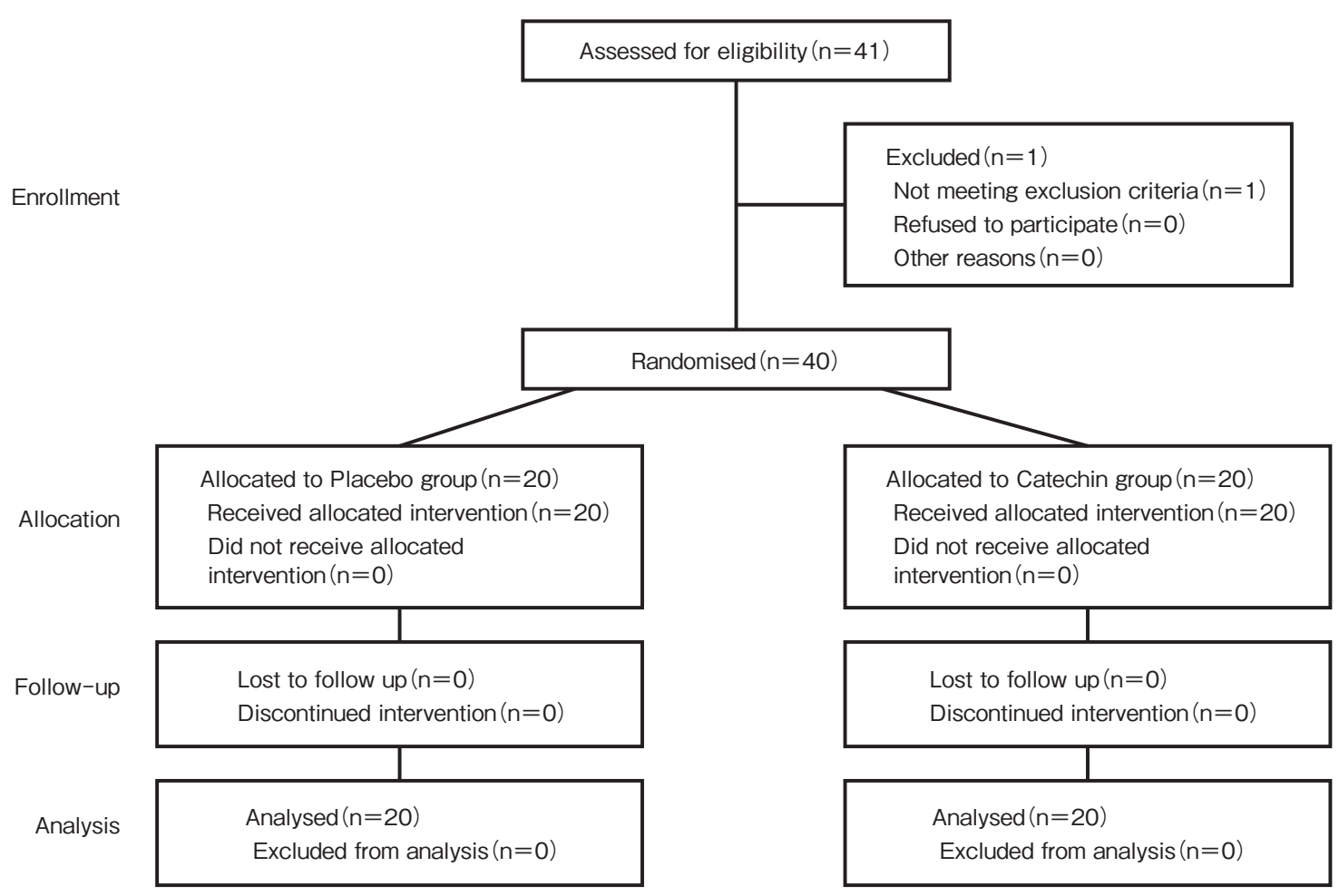

Fig. Flow chart of the study

laboratory tests, was performed using Fisher's exact test and an unpaired $t$ test. All statistical analyses were performed using $\mathrm{R}$ for Windows release 2.6.2 (R Development Core Team, 2008).

\section{Results}

The study flow chart is shown in Figure. Forty-one volunteers were recruited. On the basis of the exclusion criteria, a male volunteer was excluded because of hepatic dysfunction, leaving 40 subjects to be allocated randomly to the catechin group or the placebo group. All 40 subjects completed the study, and there were no withdrawals. Adherence with the test capsules was $98.3 \%$ in the catechin group and $98.6 \%$ in the placebo group.

The baseline characteristics are presented in Table 1. All 40 subjects ( 17 men, 23 women), were Japanese, aged between 40 and 63 years $(49 \pm 6.7$ years), and had a mean body mass index of $21.1 \mathrm{~kg} / \mathrm{m}^{2}$. The average of the subjects' usual tea drinking was 591 $\mathrm{mL} /$ day, which corresponded to approximately 2 PET plastic bottles of commercial green tea in Japan. No significant differences were observed among the 2 groups with respect to the values of the parameters shown in Table 1. The plasma levels of catechins (EGCg, EGCg3” Me) increased significantly in the catechin group compared with that in the placebo group ( $\triangle \mathrm{EGCg}, P<0.001 ; \Delta \mathrm{EGCg} 3 ” \mathrm{Me}, P<0.001$, Table 2).

The chromosomal damage and oxidative stress marker analysis data for each group are shown in Table 3. An assessment of the MNi frequency in the peripheral blood lymphocytes did not show a significant difference between the groups $(P=0.924)$. There was no significant correlation between the change in $\mathrm{MNi}$ frequency and plasma catechins (EGCg, $\mathrm{r}=0.028, P=0.864 ; \mathrm{EGCg} 3 " \mathrm{Me}, \mathrm{r}=0.075, P$ $=0.645)$. Also there were no significant differences in urinary $8-\mathrm{OHdG}$, isoprostane, lymphocyte and plasma vitamin $\mathrm{C}$ levels between the 2 groups.

The serum lipid, folic acid, and total homocysteine analyses data for each group are shown in Table 4. LDL-cho was significantly decreased by $7.6 \%$ postintervention compared with pre-intervention in the catechin group $(P=0.007)$, and there was a decreased tendency in the catechin group compared with the placebo group (Table $4, P=0.105$ ). In contrast, the TG level increased by $24.5 \%(P=0.104)$ in the catechin group, and the TG level of the catechin group was significantly different from that of the placebo group $(P=0.019)$.

Serum folic acid level was significantly decreased 
Table 1 Baseline characteristics of subjects in the placebo and catechin groups

\begin{tabular}{lcccc}
\hline & All subjects & placebo & catechin \\
$\mathrm{n}=20$ & $\mathrm{n}=20$ & $P$ value \\
& $\mathrm{n}=40$ & $49 \pm 6.9$ & $49 \pm 6.7$ & 0.963 \\
Age (year) & $49 \pm 6.7$ & $9 / 11$ & $8 / 12$ & 1.000 \\
Sex (Men/Women) & $17 / 23$ & $21.3 \pm 2.7$ & $20.8 \pm 2.7$ & 0.557 \\
BMI (kg/m $)$ & $21.1 \pm 2.7$ & $671 \pm 433$ & $519 \pm 269$ & 0.453 \\
Tea drinking (mL/day) & $591 \pm 359$ & $16.7 \pm 8.0$ & $14.9 \pm 7.5$ & 0.335 \\
MNi frequency (\%) & $15.8 \pm 7.7$ & $5.0 \pm 3.0$ & $4.3 \pm 2.9$ & 0.402 \\
8-OHdG (ng/mg CRE) & $4.6 \pm 2.9$ & $167.1 \pm 51.2$ & $328.9 \pm 724.7$ & 0.892 \\
Isoprostane (pg/mg CRE) & $248.0 \pm 513.6$ & $22.8 \pm 6.0$ & $22.4 \pm 5.7$ & 0.655 \\
Lymphocyte vitamin C (nmol/mg protein) & $22.6 \pm 5.8$ & $55.7 \pm 15.2$ & $53.5 \pm 11.6$ & 0.989 \\
Plasma vitamin C ( $\mu$ mol/L) & $54.6 \pm 13.4$ & $0.010 \pm 0.026$ & $0.025 \pm 0.040$ & 0.118 \\
EGCg ( $\mu$ g/mL) & $0.017 \pm 0.034$ & $205.9 \pm 29.9$ & $208.5 \pm 28.0$ & 0.778 \\
T-cho (mg/dL) & $207.2 \pm 28.6$ & $65.8 \pm 13.2$ & $67.7 \pm 16.4$ & 0.681 \\
HDL-cho (mg/dL) & $66.7 \pm 14.7$ & $121.4 \pm 29.3$ & $122.5 \pm 26.7$ & 0.902 \\
LDL-cho (mg/dL) & $121.9 \pm 27.7$ & $97.4 \pm 69.1$ & $89.1 \pm 38.9$ & 0.968 \\
TG (mg/dL) & $93.2 \pm 55.5$ & $6.1 \pm 2.4$ & $5.5 \pm 1.7$ & 0.285 \\
Folic acid $(\mathrm{ng} / \mathrm{mL})$ & $5.8 \pm 2.1$ & $9.4 \pm 3.7$ & $8.2 \pm 2.3$ & 0.402 \\
Total homocysteine (nmol/mL) & $8.8 \pm 3.1$ & & \\
\hline
\end{tabular}

Data are expressed as mean (SD) or number. None of the differences between the groups were statistically significant.

Table 2 Plasma levels of catechins

\begin{tabular}{|c|c|c|c|c|c|}
\hline Variable & Study group & $\begin{array}{l}\text { Pre-intervention } \\
\text { (PRE) }\end{array}$ & $\begin{array}{l}\text { Post-intervention } \\
\quad(\text { POST })\end{array}$ & Delta (POST-PRE, $\Delta$ ) & $\begin{array}{c}P \text { value (Difference } \\
\text { between groups) }\end{array}$ \\
\hline \multirow{2}{*}{$\operatorname{EGCg}(\mu \mathrm{g} / \mathrm{mL})$} & placebo & $0.03 \pm 0.04$ & $0.01 \pm 0.03$ & $-0.01 \pm 0.04$ & \multirow{2}{*}{$<0.001^{*}$} \\
\hline & catechin & $0.01 \pm 0.03$ & $0.12 \pm 0.06$ & $0.12 \pm 0.07$ & \\
\hline \multirow{2}{*}{ EGCg3” Me $(\mu \mathrm{g} / \mathrm{mL})$} & placebo & $0.00 \pm 0.00$ & $0.00 \pm 0.00$ & $0.00 \pm 0.00$ & \multirow{2}{*}{$<0.001^{*}$} \\
\hline & catechin & $0.00 \pm 0.00$ & $0.08 \pm 0.03$ & $0.08 \pm 0.03$ & \\
\hline
\end{tabular}

placebo group $(n=20)$, catechin group $(n=20) . \Delta:$ delta values were calculated by subtracting the value of PRE from the value of POST. $*: P<0.001$, compared with placebo.

Table 3 Effects of tea catechins on oxidative stress markers

\begin{tabular}{|c|c|c|c|c|c|c|}
\hline Variable & Study group & $\begin{array}{l}\text { Pre- } \\
\text { intervention } \\
\text { (PRE) }\end{array}$ & $\begin{array}{l}\text { Post- } \\
\text { intervention } \\
\text { (POST) }\end{array}$ & $\begin{array}{c}P \text { value } \\
\text { (Difference } \\
\text { within groups) }\end{array}$ & $\begin{array}{l}\text { Delta (POST- } \\
\quad \text { PRE, } \Delta)\end{array}$ & $\begin{array}{c}P \text { value } \\
\text { (Difference } \\
\text { between groups) }\end{array}$ \\
\hline \multirow{2}{*}{ MNi frequency $(\%)$} & placebo & $16.7 \pm 8.0$ & $19.0 \pm 9.2$ & 0.239 & $2.3 \pm 7.8$ & \multirow{2}{*}{0.924} \\
\hline & catechin & $14.9 \pm 7.5$ & $17.5 \pm 9.7$ & 0.144 & $2.5 \pm 6.9$ & \\
\hline \multirow{2}{*}{ 8-OHdG（ng/mg CRE） } & placebo & $5.0 \pm 3.0$ & $3.9 \pm 1.7$ & 0.055 & $-1.1 \pm 2.5$ & \multirow{2}{*}{0.313} \\
\hline & catechin & $4.3 \pm 2.9$ & $4.2 \pm 3.3$ & 0.409 & $-0.1 \pm 4.3$ & \\
\hline \multirow{2}{*}{$\begin{array}{l}\text { Isoprostane } \\
\text { (pg/mg CRE) }\end{array}$} & placebo & $167.1 \pm 51.2$ & $194.6 \pm 113.8$ & 0.332 & $9.2 \pm 42.5$ & \multirow{2}{*}{0.463} \\
\hline & catechin & $328.9 \pm 724.7$ & $298.3 \pm 529.2$ & 0.648 & $-30.7 \pm 220.6$ & \\
\hline \multirow{2}{*}{$\begin{array}{l}\text { Lymphocyte vitamin } \mathrm{C} \\
\text { (nmol/mg protein) }\end{array}$} & placebo & $22.8 \pm 6.0$ & $19.9 \pm 4.1$ & $0.022^{\dagger}$ & $-2.9 \pm 5.0$ & \multirow{2}{*}{0.641} \\
\hline & catechin & $22.4 \pm 5.7$ & $20.3 \pm 6.7$ & 0.057 & $-2.1 \pm 4.3$ & \\
\hline \multirow{2}{*}{$\begin{array}{l}\text { Plasma vitamin C } \\
(\mu \mathrm{mol} / \mathrm{L})\end{array}$} & placebo & $55.7 \pm 15.2$ & $50.7 \pm 14.5$ & 0.083 & $-5.0 \pm 12.2$ & \multirow{2}{*}{0.121} \\
\hline & catechin & $53.5 \pm 11.6$ & $53.8 \pm 15.6$ & 0.882 & $0.3 \pm 7.6$ & \\
\hline
\end{tabular}

placebo group $(n=20)$, catechin group $(n=20) . \Delta:$ delta values were calculated by subtracting the value of PRE from the value of POST. $\dagger: P<0.05$, compared with PRE (PRE vs POST). 
Table 4 Effects of tea catechins on serum lipid, folic acid, and total homocysteine levels

\begin{tabular}{|c|c|c|c|c|c|c|}
\hline Variable & Study group & $\begin{array}{l}\text { Pre- } \\
\text { intervention } \\
(\mathrm{PRE})\end{array}$ & $\begin{array}{l}\text { Post- } \\
\text { intervention } \\
(\text { POST) }\end{array}$ & $\begin{array}{c}P \text { value } \\
\text { (Difference } \\
\text { within group) }\end{array}$ & $\begin{array}{c}\text { Delta (POST- } \\
\text { PRE, } \Delta)\end{array}$ & $\begin{array}{c}P \text { value } \\
\text { (Difference } \\
\text { between groups) }\end{array}$ \\
\hline \multirow{2}{*}{ Total-cho $(\mathrm{mg} / \mathrm{dL})$} & placebo & $205.9 \pm 29.9$ & $202.2 \pm 27.9$ & 0.269 & $-3.7 \pm 14.5$ & \multirow{2}{*}{0.356} \\
\hline & catechin & $208.5 \pm 28.0$ & $200.4 \pm 26.0$ & 0.351 & $-8.2 \pm 14.7$ & \\
\hline \multirow{2}{*}{ HDL-cho $(\mathrm{mg} / \mathrm{dL})$} & placebo & $65.8 \pm 13.2$ & $65.6 \pm 13.7$ & 0.912 & $-0.2 \pm 6.0$ & \multirow{2}{*}{0.442} \\
\hline & catechin & $67.7 \pm 16.4$ & $66.1 \pm 17.8$ & 0.286 & $-1.7 \pm 5.5$ & \\
\hline \multirow{2}{*}{ LDL-cho $(\mathrm{mg} / \mathrm{dL})$} & placebo & $121.4 \pm 29.3$ & $119.4 \pm 28.2$ & 0.503 & $-2.0 \pm 13.1$ & \multirow{2}{*}{0.105} \\
\hline & catechin & $122.5 \pm 26.7$ & $113.2 \pm 23.1$ & $0.007^{\dagger \dagger}$ & $-9.3 \pm 13.7$ & \\
\hline \multirow{2}{*}{$\mathrm{TG}(\mathrm{mg} / \mathrm{dL})$} & placebo & $97.4 \pm 69.1$ & $82.1 \pm 51.1$ & 0.086 & $-15.3 \pm 41.7$ & \multirow{2}{*}{$0.019^{*}$} \\
\hline & catechin & $89.1 \pm 38.9$ & $110.8 \pm 54.0$ & 0.104 & $21.8 \pm 52.9$ & \\
\hline \multirow{2}{*}{ Folic acid $(\mathrm{ng} / \mathrm{mL})$} & placebo & $6.1 \pm 2.4$ & $6.3 \pm 2.6$ & 0.563 & $0.2 \pm 1.4$ & \multirow[b]{2}{*}{0.073} \\
\hline & catechin & $5.5 \pm 1.7$ & $4.9 \pm 2.2$ & $0.043^{\dagger}$ & $-0.5 \pm 1.1$ & \\
\hline \multirow{2}{*}{$\begin{array}{l}\text { Total homocysteine } \\
(\mathrm{nmol} / \mathrm{mL})\end{array}$} & placebo & $9.4 \pm 3.7$ & $9.7 \pm 4.0$ & 0.896 & $0.3 \pm 1.6$ & \multirow{2}{*}{$0.029^{*}$} \\
\hline & catechin & $8.2 \pm 2.3$ & $9.6 \pm 2.7$ & $<0.001^{\dagger+\dagger}$ & $1.4 \pm 1.2$ & \\
\hline
\end{tabular}

placebo group $(n=20)$, catechin group $(n=20) . \Delta:$ delta values were calculated by subtracting the value of PRE from the value of POST. $\dagger: P<0.05$, $\dagger \dagger: P<0.01$, $\dagger \dagger \dagger: P<0.001$, compared with PRE (PRE vs POST). $*: P<0.05$, compared with placebo.

by $9.1 \%$ post-intervention compared with preintervention in the catechin group $(P=0.043)$, and there was a decreased tendency between the 2 groups $(P=0.073)$. The total homocysteine level was significantly increased by $17.1 \%$ post-intervention compared with pre-intervention in the catechin group $(P<0.001)$, and there was a significant difference between the groups $(P=0.029)$.

No serious adverse events including laboratory change were observed during the study. In both groups, digestive symptoms appeared as an adverse event, but were relativity mild (placebo group, soft feces, $\mathrm{n}=1$; catechin group, constipation, $\mathrm{n}=2$ ). There were no significant differences in adverse events or laboratory results between the catechin and placebo groups.

\section{Discussion}

It is generally known that DNA and chromosomal damage are responsible for the initiation and evolution of cancer and for the acceleration of aging ${ }^{21,25)}$. The MNi frequency of the CBMN assay, which is one of the main products of chromosomal damage, is measured as a reliable high-sensitive genotoxic marker, and has recently been attempted to be used as an oxidative stress marker ${ }^{21}$. We evaluated the MNi frequency in middle-aged healthy subjects and observed no significant differences between the catechin and placebo groups. Therefore, the results showed that chromoso- mal damage and genotoxicity were not accelerated within a week of consuming a large amount of tea catechins.

Urinary $8-\mathrm{OHdG}$ is known to be the main product of the oxidative damage of DNA, and urinary isoprostane is known to be one of the main products of the oxidative damage of cell membrane $e^{26)}$. Vitamin $\mathrm{C}$ is known to be an antioxidant and can be measured as an index of antioxidative potential ${ }^{27}$. To measure vitamin $\mathrm{C}$ level, lymphocyte vitamin $\mathrm{C}$ was considered to reflect the state of vitamin $\mathrm{C}$ stockpiling in tissues, and was not easily influenced by diet or daily circadian fluctuation ${ }^{28)}$. We evaluated the antioxidative effect by using the measurements of urinary 8OHdG, isoprostane, and lymphocyte and plasma vitamin $\mathrm{C}$ levels, and showed no significant differences between the groups. The results might suggest that these oxidative stress markers were not affected during the short intervention period of a week, with the amount of tea catechins used.

With regard to lipid regulation, LDL-cho in the catechin group significantly decreased compared with pre-intervention period, and there was a decreased tendency in the catechin group compared with the placebo group, but the difference was not significant $(P=0.105)$. There were no significant differences between the groups in terms of either total or HDLcho levels. Conversely, the TG level significantly increased in the catechin group. The serum TG level 
was influenced by various factors such as the recent intake of food, beverage, and alcohol ; therefore, the results need to be carefully interpreted. We calculated the total energy and lipid levels in the diet of each participant and found that these amounts widely varied in each individual and in each period as follows : The median total energy level was $1765 \mathrm{kcal} /$ day for the pre-intervention period (range, 453-2985 $\mathrm{kcal} /$ day) and $1744 \mathrm{kcal} /$ day (range, 931-3002 kcal/ day) for the intervention period. The median total lipid level was $55 \mathrm{~g} /$ day (range, 11-136 g/day) for the pre-intervention period and $54 \mathrm{~g} /$ day (range, 11$122 \mathrm{~g}$ /day) for the intervention period. However, it was reported that lipoprotein lipase (LPL), which degraded TG to non-esterified fatty acid and glycerol, was inhibited by tea catechins ${ }^{29}$, which may indicate a possible mechanism of TG elevation. However, it was also reported that tea catechins inhibited the absorption of TG in the small intestines, and decreased the serum TG levels ${ }^{9}$. Further clinical studies should be performed with well-controlled diets for a few days before blood sampling to elucidate the effect of tea catechins on the serum TG levels.

Serum folic acid showed a tendency to decrease with the consumption of tea catechins. Tea catechins are reported to inhibit conjugase, an enzyme involved in the absorption of folic acid, in the small intestine epithelium ${ }^{30)}$. Therefore, the results support the report that the absorption of folic acid was inhibited by tea catechins. Moreover, the total homocysteine level significantly increased by consuming tea catechins. The serum homocysteine level is influenced by folic acid, vitamin B6, and vitamin B12 ; of these, folic acid is considered to be the main factor influencing the serum homocysteine level. There was also a negative correlation between folic acid and homocysteine levels ${ }^{31)}$. It was thought that the total homocysteine level increased because of the decrease in folic acid level in the catechin group. The results imply that folic acid should be added to the diet when large amounts of catechins are being consumed. In daily tea drinking, however, where folic acid is contained in green tea, the decrease in folic acid by catechins may not have any influence on human health.

Our study has certain limitations. First, the duration of intervention was relatively shorter than that used in published studies on the effectiveness of consuming large amounts of catechins ${ }^{7,13)}$. However, the amount of catechins used in our study corresponds to consuming approximately 10 cups of green tea per day and is almost 2-fold higher than the amount reported by Hakim et $\mathrm{al}^{7)}$ and Davies et $\mathrm{al}^{13)}$ (4-5 cups per day). The safety of using such large amounts of catechins in humans has not yet been well established $^{32)}$; therefore, we investigated the effects of only short-term consumption in order to ensure the safety of the participants. Furthermore, we determined the amounts of catechins on the basis of the effects of EGCg on plasma superoxide scavenging activity, at 2 hours after oral ingestion of catechins ${ }^{33)}$. However the effectiveness of catechins on our outcome measures might be underestimated because of the short study periods. Second, a small sample size was used. Although the sample size was determined on the basis of feasibility, the statistical power seemed to be weakened with respect to confirming the effectiveness of catechins. For clarifying the effects of these limitations, additional long-term and large-scale randomized trials should be performed.

In conclusion, a large amount of tea catechins, which corresponds to approximately 10 cups of green tea per day for 1 week, seemed to be well tolerated, and did not influence chromosomal damage and the oxidative stress markers. Further long-term and large-scale studies are required to clarify the longterm effect of the consumption of a large amount of tea catechins on these markers as well as on improving dyslipidemia.

\section{Acknowledgements}

We gratefully acknowledge the volunteers who participated in the study, the clinical research coordinators and other medical staffs at the Shizuoka General Hospital, and an undergraduate student (Ms. Miki Ito) at the University of Shizuoka, for their dedicated cooperation.

\section{Conflict of Interest}

This work was supported by a grant from the Japanese Ministry of Health, Labour, and Welfare, and a grant from ITO EN, Ltd.

\section{References}

1) Rice-Evans CA, Miller NJ, Paganga G. Structure-antioxidant activity relationships of flavonoids and phenolic acids. Free Radic Biol Med. 1996 ; 20(7) : 933-56.

2) Khan N, Mukhtar H. Tea polyphenols for health promotion. Life Sci. $2007 ; 81(7): 519-33$.

3) Cabrera C, Artacho R, Gimenez R. Beneficial effects of green tea-a review. J Am Coll Nutr. 2006 ; 25(2) : 79-99.

4) Da Silva EL, Piskula M, Terao J. Enhancement of antioxidative 
ability of rat plasma by oral administration of $(-)$-epicatechin. Free Radic Biol Med. 1998 : 24(7-8) : 1209-16.

5) Vinson JA, Jang J, Yang J, Dabbagh Y, Liang X, Serry M, et al Vitamins and especially flavonoids in common beverages are powerful in vitro antioxidants which enrich lower density lipoproteins and increase their oxidative resistance after ex vivo spiking in human plasma. J Agric Food Chem. 1999; 47 (7) :25024.

6) Sugisawa A, Umegaki K. Physiological concentrations of (-) epigallocatechin-3-O-gallate (EGCg) prevent chromosomal damage induced by reactive oxygen species in WIL2-NS cells. $J$ Nutr. 2002 ; 132(7) : 1836-9.

7) Hakim IA, Harris RB, Brown S, Chow HH, Wiseman S, Agarwal $\mathrm{S}$, et al. Effect of increased tea consumption on oxidative DNA damage among smokers : a randomized controlled study. J Nutr. $2003 ; \mathbf{1 3 3}(10): 3303 \mathrm{~S}-9 \mathrm{~S}$.

8) Khan N, Mukhtar H. Multitargeted therapy of cancer by green tea polyphenols. Cancer Lett. 2008 ; 269 (2) : 269-80.

9) Ikeda I, Imasato Y, Sasaki E, Nakayama M, Nagao H, Takeo T, et al. Tea catechins decrease micellar solubility and intestinal absorption of cholesterol in rats. Biochim Biophys Acta. 1992 ; $1127(2): 141-6$.

10) Kajimoto O, Kajimoto $Y$, Yabune M, Nozawa A, Nagata K, Kakuda T. Tea catechins reduce serum cholesterol levels in mild and borderline hypercholesterolemia patients. J Clin Biochem Nutr. 2003 ; 33(3) : 101-11.

11) Kajimoto O, Kajimoto $Y$, Yabune M, Nakamura T, Kotani K, Suzuki Y, et al. Tea catechins with a galloyl moiety reduce body weight and fat. J Health Sci. $2005 ; 51(2):$ 161-71.

12) Koo SI, Noh SK. Green tea as inhibitor of the intestinal absorption of lipids : potential mechanism for its lipid-lowering effect. J Nutr Biochem. 2007 ; 18(3) : 179-83.

13) Davies MJ, Judd JT, Baer DJ, Clevidence BA, Paul DR, Edwards $\mathrm{AJ}$, et al. Black tea consumption reduces total and LDL cholesterol in mildly hypercholesterolemic adults. J Nutr. 2003 ; 133(10) : 3298S-302S.

14) Dulloo AG, Duret C, Rohrer D, Girardier L, Mensi N, Fathi M, et al. Efficacy of a green tea extract rich in catechin polyphenols and caffeine in increasing 24-h energy expenditure and fat oxidation in humans. Am J Clin Nutr. $1999 ; 70$ (6) ; 1040-5.

15) Negishi H, Xu JW, Ikeda K, Njelekela M, Nara Y, Yamori Y. Black and green tea polyphenols attenuate blood pressure increases in stroke-prone spontaneously hypertensive rats. $J$ Nutr. $2004 ; \mathbf{1 3 4}(1): 38-42$.

16) Yamada $H$, Tateishi M, Harada K, Ohashi T, Shimizu T, Atsumi $\mathrm{T}$, et al. A randomized clinical study of tea catechin inhalation effects on methicillin-resistant Staphylococcus aureus in disabled elderly patients. J Am Med Dir Assoc. 2006 ; 7 (2) : 79-83.

17) Yamada H, Takuma N, Daimon T, Hara Y. Gargling with tea catechin extracts for the prevention of influenza infection in elderly nursing home residents : a prospective clinical study. $J$ Altern Complement Med. $2006 ; 12(7)$ : 669-72.

18) Niino H, Obara K, Sagesaka Y, Iigaya N, Ogawa K, Hayashi M, et al. Clinical effect and safety of oolong tea "ogonkei" for seasonal allergic rhino-conjunctivitis caused by pollen.J Trad Med. 2008 ; $25(1): 10-7$.

19) Goto T, Yoshida Y, Kiso M, Nagashima H. Simultaneous analysis of individual catechins and caffeine in green tea.J Chromatogr A. $1996 ; \mathbf{7 4 9}(1-2): 295-9$.

20) Fenech M. Cytokinesis-block micronucleus cytome assay. Nat Protoc. 2007 ; 2 (5) : 1084-104.

21) Fenech M. Chromosomal biomarkers of genomic instability relevant to cancer. Drug Discov Today. $2002 ; 7$ (22) : 1128-37.

22) Umegaki K, Yoshimura M, Nishimuta M, Esashi T. A practical method for determination of vitamin $\mathrm{C}$ in plasma by high performance liquid chromatography with an electrochemical detector. J Jpn Soc Nutr Food Sci. 1999 ; 52(2) : 107-11.

23) Washko PW, Hartzell WO, Levine M. Ascorbic acid analysis using high-performance liquid chromatography with coulometric electrochemical detection. Anal Biochem. 1989 ; 181 (2) : 27682.

24) Unno T, Sagesaka YM, Kakuda T. Analysis of tea catechins in human plasma by high-performance liquid chromatography with solid-phase extraction. J Agric Food Chem. 2005 ; 53(26) : 9885-9.

25) Santella RM. DNA damage as an intermediate biomarker in intervention studies. Proc Soc Exp Biol Med. 1997 ; 216(2) : 16671.

26) Mayne ST. Antioxidant nutrients and chronic disease : use of biomarkers of exposure and oxidative stress status in epidemiologic research. J Nutr. 2003 ; 133 (Suppl 3) : 933S-40S.

27) Riso P, Visioli F, Erba D, Testolin G, Porrini M. Lycopene and vitamin $\mathrm{C}$ concentrations increase in plasma and lymphocytes after tomato intake. Effects on cellular antioxidant protection. Eur J Clin Nutr. $2004 ; 58(10):$ 1350-8.

28) Emadi-Konjin P, Verjee Z, Levin AV, Adeli K. Measurement of intracellular vitamin $\mathrm{C}$ levels in human lymphocytes by reverse phase high performance liquid chromatography (HPLC). Clin Biochem. $2005 ; 38(5): 450-6$.

29) Pak-Dek MS, Abdul-Hamid A, Osman A, Soh CS. Inhibitory effect of Morinda citrifolia L. on lipoprotein lipase activity. J Food Sci. $2008 ; 73(8)$ : C595-8.

30) Alemdaroglu NC, Dietz U, Wolffram S, Spahn-Langguth H, Langguth P. Influence of green and black tea on folic acid pharmacokinetics in healthy volunteers : potential risk of diminished folic acid bioavailability. Biopharm Drug Dispos. $2008 ; 29(6): 335-48$.

31) Swain RA, St Clair L. The role of folic acid in deficiency states and prevention of disease. J Fam Pract. 1997 ; 44(2) : 138-44.

32) Chacko SM, Thambi PT, Kuttan R, Nishigaki I. Beneficial effects of green tea : a literature review. Chin Med. $2010 ; 5: 13$.

33) Unno T, Aihara T, Sagesaka Y, Kakuda T, Matsui T, Arakawa Y. Increase in plasma superoxide scavenging activity after ingesting (-)-epigallocatechin gallate (EGCG). Anti-Aging Medicine. $2006 ; 2: 242-6$ (in Japanese). 